\title{
Road plates with increased strength characteristics
}

\author{
Igor Ivanov ${ }^{1, *}$, Andrey Komarov², and Victoria Rosina ${ }^{2}$ \\ ${ }^{1}$ East-Siberian State University of Technologies and Management, 670033, Klyuchevskaia str., 40v/1, \\ Ulan-Ude, Russia \\ ${ }^{2}$ Irkutsk National Research Technical University, 664074, Lermontova str., 83, Irkutsk, Russia
}

\begin{abstract}
The issues of creating road plates with increased operational properties are considered in this paper. Monolithic concrete has a number of disadvantages, such as a long period of strength accumulation, temperature and humidity regime, and the inability to produce works throughout the year. The analyzed material for the production of road slabs (fiber concrete) makes it possible to produce plates with increased strength characteristics, to prolong service life, and to improve their physical and mechanical characteristics.
\end{abstract}

Covering roads with more durable material than the embankment of the road itself, has a long tradition, and its improvement is associated with technical and technological achievements of mankind. The first roads in ancient Rome were covered with limestone slabs, and some of these roads have survived to this day.

There were attempts to cover roads with wood. These were so called end-face roads, designed by the Russian engineer V.P. Guryev. In St. Petersburg, several streets were paved based on this technology. The trunk of the tree was sawed to a thickness of up to $20 \mathrm{~cm}$ and chunks were placed on the prepared surface of the embankment close to each other. Between these chunks, there were emptiness and they were filled with soil, otherwise in the future potholes formed. In the future, the chunks obtained a form of hexahedrons, which closely adhered to each other.

The next step in the development of paving is the application of clinker, that is, a special brick for paving roads. It was made from special refractory clays and fired until complete sintering. Upon impact, the clinker produced a clean and clear ringing. This is why the word clinker is translated from German as "bang". This technology was widely used in Western Europe in the $17^{\text {th }}-18^{\text {th }}$ centuries. In Russia, the first clinker plant was built in the late $18^{\text {th }}$ century in the city of Chernigov. Clinker was made in sizes of $10-20 \mathrm{~cm}$ and of height up to $10 \mathrm{~cm}$.

Simultaneously with clinker, paving roads with stones was introduced. This technology is used today, though in the smallest amounts.

In Russia, the asphalt concrete coating was first performed in 1873 (Bakhilovskaya dacha of the Syzran uyezd).

*Corresponding author: Ivanova-2006@ mail.ru 
In modern Russia, rapid growth of the asphalt plants began in the 1950s due to the intensive development of the automobile industry. The quality of the asphalt roads at that time should be assessed as low.

A real breakthrough in the road construction is connected with the use of concrete, and this technology has been used en masse throughout the world. Initially various rocks of volcanic origin (tuff, ash, and pumice) in the calcareous solutions were introduced in finely ground form. Later, Portland cement was used as an astringent.

Currently, various concrete covers are used: monolithic and prefabricated, single-layer and double-layer, reinforced and unreinforced.

The thickness of the concrete cover is, as a rule, $20-25 \mathrm{~cm}$. The concrete mixture is laid at full thickness in one process, with a width of 6-9 $\mathrm{m}$ that corresponds to two lanes.

Concrete road coverings are in 5-6 times more durable than asphalt concrete, their service life can reach 50 years and more. They are resistant to aggressive environment, provide a high grip of the wheels of vehicles with the road, and the road wears out a little.

The disadvantage of monolithic concrete is the impossibility of year-round production. Also, there are problems of providing a temperature-humidity regime for the concrete strength accumulation, and the duration of the accumulation of strength is quite large. These features inhibit the use of monolithic concrete in the construction of highways.

The technology of covering roadbed with individual slabs has come to substitute the monolithic concrete technology. The principal construction of this cover is shown on the Figure 1.

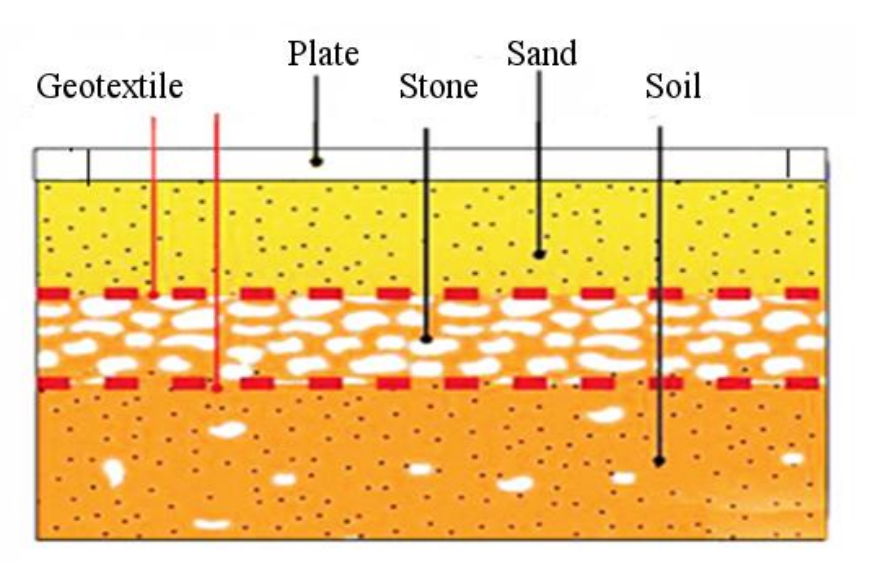

Fig. 1. Scheme of covering a road with reinforced concrete slabs.

But this technology also does not meet all the requirements, as joints of prefabricated plates do not provide the transfer of forces and moments from the slab to the slab. Through the seams, there is a squeezing of sand and underlying soil. The end of the plate works like a console, and in these places cracks and potholes are formed. In the middle of the plate, the armature fulfills its function, as the top of the plate works to compress, and the bottom to stretch (Figure 2). 


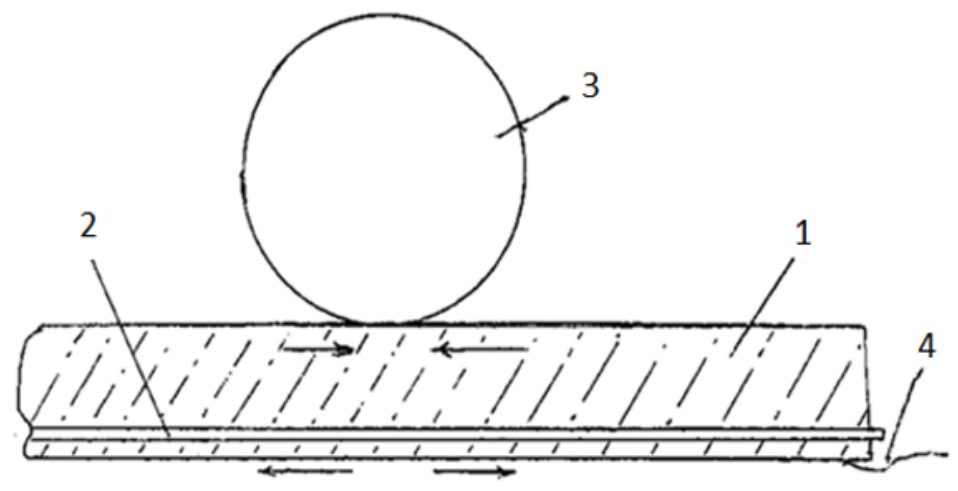

Fig. 2. 1 - concrete, 2 - reinforcement, 3 - wheel of the vehicle, 4 - pothole. The arrows indicate the resulting forces in the road plate when the vehicle wheel is in the middle of the plate (at the top by compression, at the bottom by stretching).

When the wheels of the vehicle approach the edge of the slab, the scheme of operation of the reinforced concrete slab completely changes. This is shown on the Figure 3.

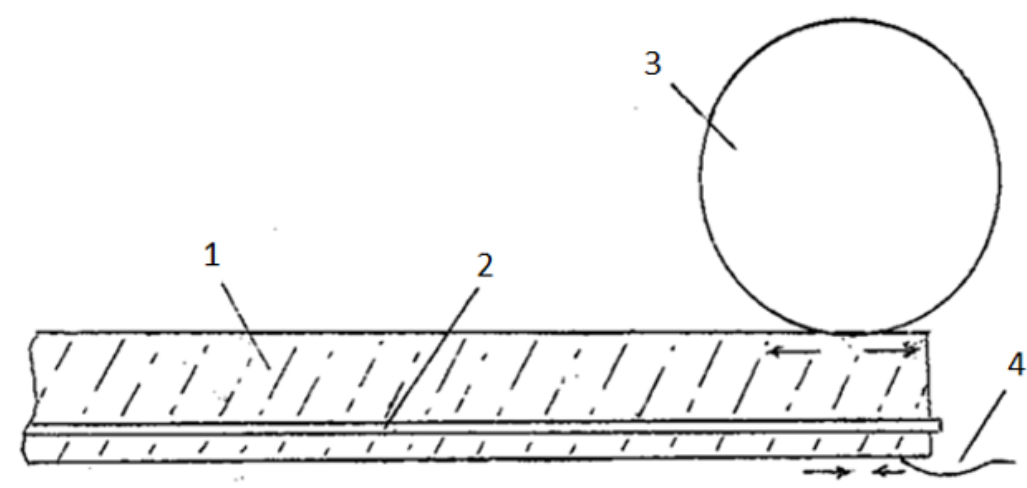

Fig. 3. The same, as on the Figure 2, but wheel of the vehicle is on the edge of the road plate.

In this case, the upper part of the plate works for stretching, and the lower part for compression. As a result, cracks are formed in the upper part of the plate, and then they are chipped. The presence of chips further increases the dynamic loads on the plate and disables it. To strengthen the extreme upper part of the plate, it is possible to lay metal armature in this zone. But taking into account the fact that the protective layer of concrete is very small, due to wear, it is possible to bare the reinforcement, which can lead to a puncture of the tire and a vehicle accident.

The connection of the slabs to the solid road surface with the help of the outlets of the working fittings on the end faces is very problematic. There are additional works on welding of armature outlets, anticorrosive coating of welded joints and embedment of joints. Quality bonding of concrete slabs and concrete embedment joints is not ensured. These sites are vulnerable, subject to mechanical destruction.

Since the concrete does not work well on stretching, cracks are formed at the edge of the plate, and then the chips are formed (Figures 4 and 5). 


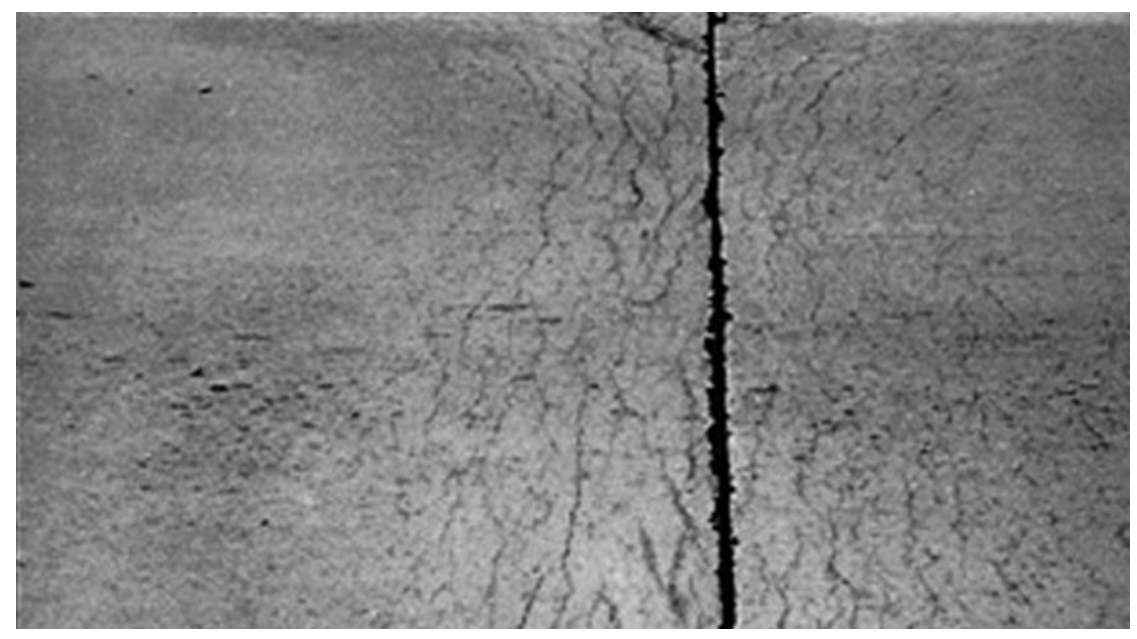

Fig. 4. View of the road plate from the top. There are cracks on the joints of the plates, formed from the fact that the upper part of the plate is stretching, and the reinforcement of this zone is not provided.

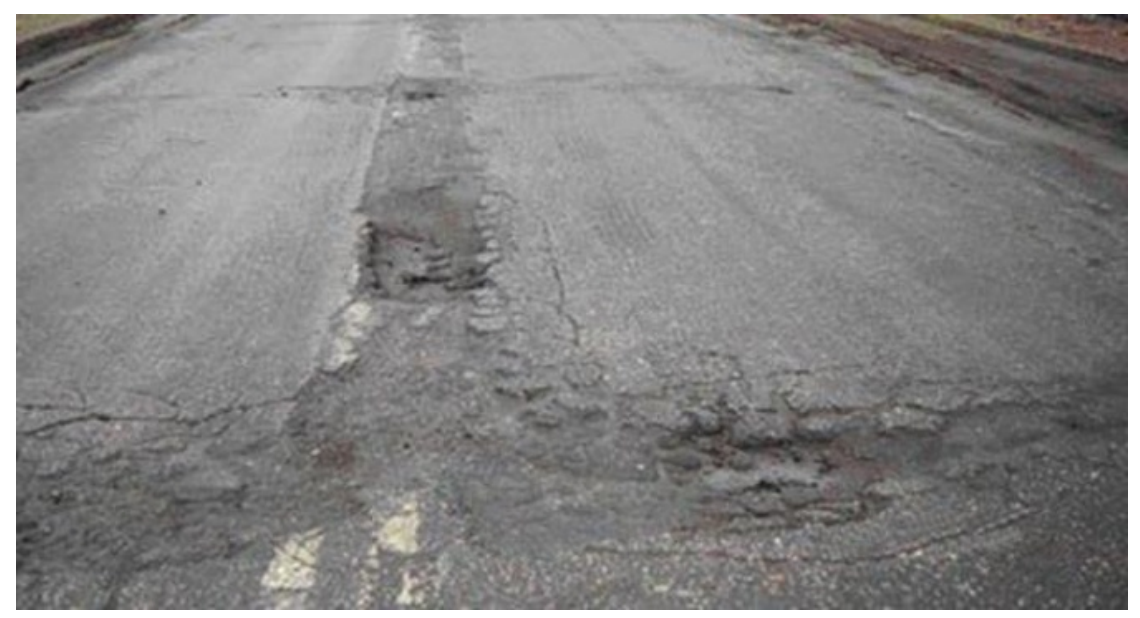

Fig. 5. View of road plate from above.

Shock loads increase, and the road plate becomes unusable. If the destroyed concrete is removed, one can find the reinforcement, located in the bottom of the road plate in complete safety.

To eliminate this disadvantage, the edge of the plate (upper part) is recommended to be made of fiber-reinforced concrete, which works well for stretching and is very resistant to cracking and chips (Figure 6). 


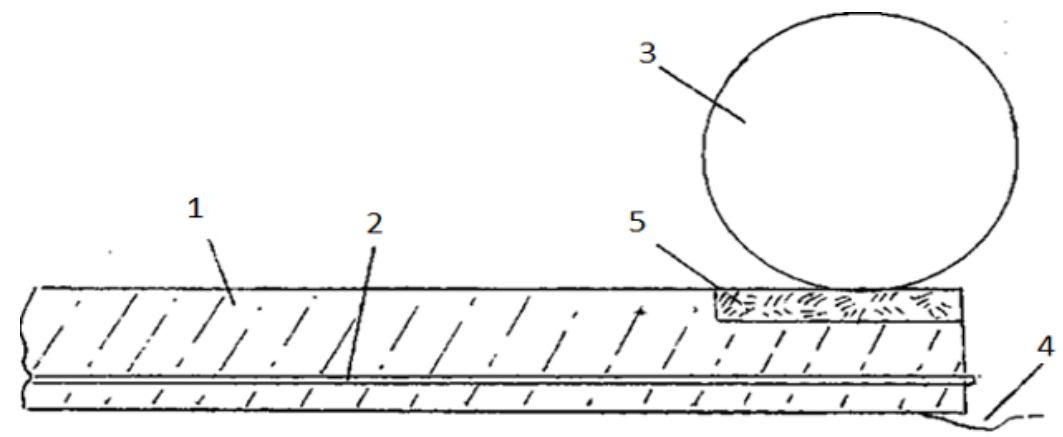

Fig. 6. Construction of a road slab with a section made of fiber concrete. 1 - concrete, 2 - reinforcement, 3 - wheel of the vehicle, 4 - pothole. The arrows show the forces that arise in the road plate when the vehicle wheel is at the edge of the plate (at the top by stretching, at the bottom by compression), 5 fiber reinforced concrete.

Fiber should be provided from fiberglass, basalt or polypropylene, that is, one that cannot harm the tire of the vehicle. Metal fiber at its bare exposure can cling to the tire, make punctures, make noise when the wheel hits. Fibers made of fiberglass, basalt or polypropylene, work well for stretching and when they are exposed, they do not harm the tire of the vehicle.

To implement this proposal - the modernization of the construction of road plates - it is necessary to make an adjustment to the technology of their production. The Figure 7 shows the scheme for manufacturing road plates using the new technology.

As with the original basic version, the standard formwork mold (1) (or stand) is used. The installation of reinforcing articles (2) (mesh or spacer) is carried out with the provision of a protective layer.

Limiters (3), delimiting the laying areas of a conventional concrete mixture (of a given class) and a fiber-reinforced concrete mixture, are installed in the mold. The distance from the end forms of the structure to the limiters is set equal to $500 \div 800 \mathrm{~mm}$. The height of the fiber-reinforced concrete layer is assumed equal to $1 / 3$ of the thickness of the road plate.

Concreting is carried out to the mark " $\mathrm{A}$ " using an ordinary concrete mixture over the entire width of the mold.

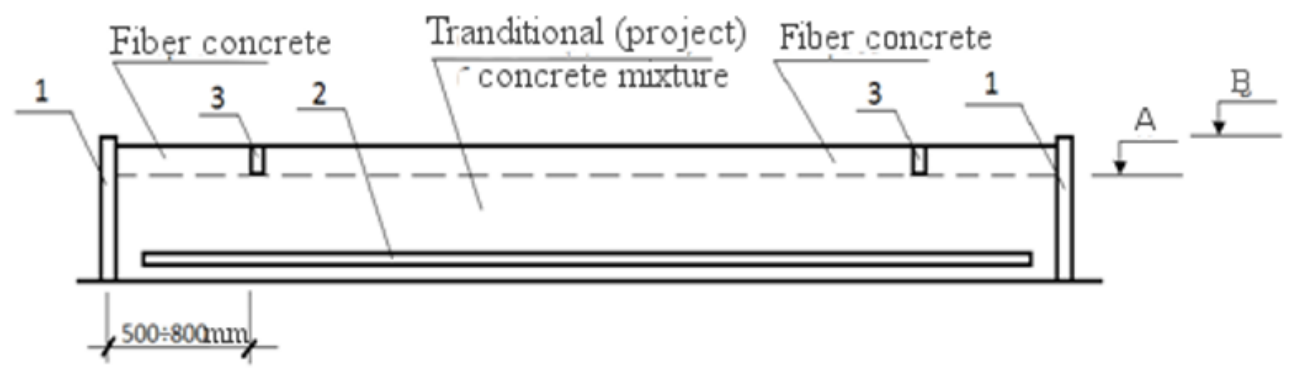

Fig. 7. 1 - formwork plate, 2 - reinforcement, 3 - limiters, A, Б - levels of concreting (stages).

Further, without interruptions, the mixture fits to the mark " $Б$ " between the limiters. Immediately or simultaneously a fiber-concrete mixture is laid in the formwork. After that, the limiters are immediately deleted. The concrete mix is compacted by surface, external vibrators or using a vibrating platform. This sequence ensures reliable conjugation and colmatation of the compositions of freshly mixed concrete mixtures (the usual design of composition for the main massif of the road plate and fiber concrete). Further, the processes 
of holding concrete (possibly using autoclave treatment) of the article take place. The above design of the road plate is characterized by reliability and durability.

\section{References}

1. V. F. Babkov, O. V. Andreev, Design of highways (Transport, Moscow, 1987)

2. S. M. Tsukovich, Technology of concrete fillers (Higher School, Moscow, 1991)

3. I. Kh. Nanazashvili, Building materials, products and structures (Higher School, Moscow, 1990)

4. Patent-2595020, bul. 23-16g.

5. M. V. Nemchinov, Science and Technology in the Road Industry, 2, 6-8 (2001)

6. A. V. Kochetkov, P. S. Susliganov, Arrangement of rough surface layers on car cover and bridge structures (INFORMVODODOR, Moscow, 2005)

7. I. A. Ivanov, A. K. Komarov, L. A. Urkhanova, From the history of road construction (IrSTU, Irkutsk, 2013)

8. Ya. R. Mytko, Evaluation of the transport and operational characteristics of highways (UNITI, Minsk, 2001)

9. Ministry of Transport of Russia, Roads at the turn of the century: figures and facts (Rosavtodor, Moscow, 2001)

10. A. E. Kazarinov, S. A. Fedorov, Reconstruction of highways: research and design solutions (Khabar. Gos., Khabarovsk, 2002)

11. M. S. Koganson, Construction and operation of highways: tasks and solutions, 20-29 (2001)

12. A. M. Sheinin, Cement concrete for road and airfield coatings (Transport, Moscow, 1991)

13. A. P. Vasiliev, Construction and operation of highways: tasks and solutions, 4-19 (2001)

14. M. V. Sadilo, R. M. Sadilo, Automobile roads: construction and operation (Phoenix, Moscow, 2011)

15. A. V. Smirnov, V. P. Podolsky, A. V. Glagoliev, P. I. Pospelov, Construction of highways: road surfaces (Akademia, Moscow, 2013) 